\title{
A Center for the Rapid Analysis of Clinical-Grade Biologics: The Biophysical Characterization of HIV-1 Env Protein ${ }^{+}$
}

\author{
José A. Lasalde-Dominicci 1,2,3,4, Abel Baerga-Ortiz ${ }^{1,5, *}$, Pearl Akamine ${ }^{1}$, \\ José A. González-Feliciano ${ }^{1}$, Coral Capó-Vélez ${ }^{1}$ and Manuel Delgado-Vélez ${ }^{1}$ \\ 1 Molecular Sciences Research Center, University of Puerto Rico, San Juan, 00926, Puerto Rico; \\ pearl.akamine@upr.edu (P.A.); jose.gonzalezfeliciano@upr.edu (J.A.G.-F.); coral.capo@upr.edu (C.C.-V.); \\ manuel.delgadovelez@upr.edu (M.D.V.) \\ 2 Department of Biology, Río Piedras Campus, University of Puerto Rico, San Juan 00926, Puerto Rico \\ 3 Department of Chemistry, Río Piedras Campus, University of Puerto Rico, San Juan 00925, Puerto Rico \\ 4 Clinical Bioreagent Center, University of Puerto Rico, San Juan 00926, Puerto Rico \\ 5 Department of Biochemistry, Medical Sciences Campus, University of Puerto Rico, San Juan 00936-5067, \\ Puerto Rico \\ * Correspondence: jlasalde@gmail.com (J.A.L.-D.), abel.baerga@upr.edu (A.B.-O.) \\ + Presented at Viruses 2020-Novel Concepts in Virology, 5-7 February 2020. \\ Published: 15 July 2020
}

\begin{abstract}
The development of a prophylactic vaccine against the human immunodeficiency virus (HIV) is of paramount importance in the global drive to halt the spread of the virus. Even after the successful discovery and initial testing of a vaccine candidate, there are hurdles associated with production yield, purification strategy, and in vitro stability that may hinder its development as a biological product. The goal of the Clinical Bioreagent Center (CBC) is to streamline the vaccine development pipeline from a promising lead to the clinic, in part by developing state-of-the-art analytical tools to characterize and to quickly monitor the quality of the HIV-1 Env protein, a new vaccine candidate. A method was developed to determine the purity of the HIV-1 Env glycoprotein by capillary electrophoresis that provides higher sensitivity of detection of impurities and better resolution as compared to regular gel electrophoresis. Using an Octet QKe system, host cell protein content was confirmed using a kit that has greater precision and linear range than available kits based on enzyme-linked immunosorbent assay (ELISA). Imaged capillary isoelectric focusing results highlight the charge heterogeneity of the recombinant HIV-1 Env protein. The binding affinity of the broadly neutralizing antibody, 4E10, to the HIV-1 Env protein was determined by biolayer interferometry. The glycan profile obtained by matrix-assisted laser desorption/ionization (MALDI) spectrometry showed that the recombinant HIV-1 Env protein glycans are distinct from SF162 gp140. These analytical tools can be implemented to ensure that the protein expression and purification conditions do not change the integrity, bioactivity, and therapeutic properties of the vaccine. The methods developed here can be qualified with current good manufacturing practices to facilitate their transfer to a biomanufacturing facility. Our experimental tools were developed to monitor the quality of the HIV-1 Env protein, with the goal of boosting production yields to expedite its success onto clinical trials.
\end{abstract}

Keywords: vaccine; analytics; HIV; envelope; manufacturing 
Funding: Supported by NIH-NIAID R01AI22935.

(c) 2020 by the authors. Licensee MDPI, Basel, Switzerland. This article is an open access article distributed under the terms and conditions of the Creative Commons Attribution (CC BY) license (http://creativecommons.org/licenses/by/4.0/). 